\title{
Abiotic Stresses and Their Effects on Plant Growth, Yield and Nutritional Quality of Agricultural Produce
}

\author{
Suresh Kumar \\ Division of Biochemistry, ICAR-Indian Agricultural Research Institute, New Delhi-110012, India.
}

How to cite this paper: Suresh Kumar. (2020) Abiotic Stresses and Their Effects on Plant Growth, Yield and Nutritional Quality of Agricultural Produce. International Journal of the Science of Food and Agriculture, 4(4), 367-378.

DOI: $10.26855 /$ ijfsa.2020.12.002

Received: September 3, 2020

Accepted: September 28, 2020

Published: October 14, 2020

${ }^{*}$ Corresponding author: Suresh $\mathrm{Ku}-$ mar, Division of Biochemistry, ICAR-Indian Agricultural Research Institute, New Delhi-110012, India. Email: sureshkumar3 in@yahoo.co.uk; sureshkumar@iari.res.in

\begin{abstract}
Abiotic stresses, like extreme temperature, drought, flood, salinity, and heavy metals, are some of the major factors that limit crop productivity and quality. Abiotic stresses considerably affect the growth, development, and productivity of crop plants, such adverse environmental conditions may reduce the performance of the crop with reduced yield from $50 \%$ to $70 \%$. Emission of greenhouse gases from different sources is believed to be one of the factors responsible for the gradual increase in the global ambient temperature (global warming). Global warming has also changed the precipitation pattern and contributing to erratic drought/flood stress. Abiotic stresses, particularly drought and heat stress, during the vegetative and reproductive stage of growth adversely affect biomass, grain yield, and quality of the produce. A combination of abiotic stresses, for example, drought and heat, have much greater effects on the yield and quality of the produce. However, responses of plants to these stresses may vary across the species, as well as at different developmental stages. Scarcity of water (drought) and higher temperature induces the stress-associated metabolic responses, and stomatal closure significantly decreases the uptake of $\mathrm{CO}_{2}$. As a result, the reduction equivalents (e.g. NADPH $+\mathrm{H}^{+}$) for $\mathrm{CO}_{2}$ fixation via the Calvin cycle declines considerably. Not only the photosynthetic process but also the biosynthetic processes involved in proteins, lipids, and minerals metabolism are affectedby adaptive responses. As a consequence of these metabolic shifts, carbohydrate, protein, lipid, and mineral compositions are significantly affected by the abiotic stresses. Although the effects of abiotic stress on the yield of cereals and grain legumes are relatively well-understood, further research on the combined effects of abiotic stresses, abiotic and biotic stresses, and their effects on crop yield and nutritional quality of the produce needs to be undertaken. Molecular genetics of the stress responses and the tolerance mechanisms are likely to pave the way forward in developing crop plants that can withstand and give economic yield under the abiotic stresses.
\end{abstract}

\section{Keywords}

Abiotic stress, Climate change, Climate-resilient agriculture, Crop yield, Drought stress, Quality of produce

\section{Introduction}

One of the serious effects of global climate change has been a continuous decline in the availability and productivity of arable land [1]. A combination of abiotic stresses, such as drought and heat, salinity and heat, etc., has been known to 
be even more destructive to crops than the individual stress alone [2, 3, 4, 5]. Not only these, but abiotic stresses are also known to influence the occurrence and spread of biotic stresses like insect pests, pathogens, weeds, etc. [6, 7, 8, 9, 10]. Reduced plant growth due to drought or heat stress is a frequent and common phenomenon world over. When both the stresses are combined, their effects on the yield of the crop are more severe than the effects of the individual stress $[11,12,13]$. Drought and heat stress are some of the problems for crop growth, development, yield, and sustainability of agriculture all over the world [14]. In the rainfed areas, effective rainfall and its distribution throughout the season are becoming highly variable, which has become a major cause of frequent drought stress in agricultural fields [15, 16, 17].

An increase in soil temperature, resulting from an increase in air temperature, becomes even more severe when it is accompanied by drought stress [5] [18] [19]. Under field conditions, water-deficit (drought) stress often occurs concurrently with high air temperature (heat stress), and now this has a become threat to agriculture and the sustainable food production world over [14] [20]. Severe stress(es) considerably affect(s) crop yield and quality. Underabiotic stress, plants face scarcity of essential factors and/or imbalanced nutrients that finally turn into decreased yield and loss of quality of the produce. Stresses also affect the accumulation of metabolites in plant's edible parts, sometimes positively by concentrating nutraceutical or stress-related metabolites which are appreciated as health-related compounds in human nutrition [21]. For example, the imposition of salt stress has recently been suggested as a potential stressor for enhancing the quality of fruits and vegetables [22].

Plants have evolved several strategies to cope up with the environmental stresses by prompt and harmonized changes at transcriptional and post-transcriptional levels, including the epigenetic regulation of gene expression [23, 24, 25, 26]. The plant uses a range of sensing and signaling mechanisms to provoke stress responses under the environmental stresses. Stress signaling involves several phytohormones to alert the plant quickly and efficiently to respond effectively [27]. Growing evidence indicates that epigenetic mechanisms are also involved in the regulation of gene expression at transcriptional and post-transcriptional levels [28]. Studies also indicate that heritable variations in economically important traits may also be caused by the underlying epigenetic variations [29, 30]. Several epigenetic mechanisms have been implicated to be involved in the regulation of stress-associated genes [31]. Epigenetic changes refer to the heritable variations in gene expression resulting from the modifications of DNA and its associated chromatin structure, of course without changing the underlying nucleotide sequence [32]. Among these epigenetic mechanisms, DNA methylation is currently the best understood. DNA (de)methylation plays an important role in (de)activating the specific genes in response to environmental stress or during developmental processes [33]. Genetic engineering for the development of stress-tolerant plants through epigenetic manipulation would require proper selection of the target sequence/gene. Artificial siRNA from the targeted gene can be utilized for the purpose. As methylation machinery of the host cell also plays an important role in DNA methylation, over-expression/silencing of methyltransferase genes and the other key factors like siRNAs can be combined. Although, these assumptions need to be validated. Further, understanding the epigenetic mechanisms of gene regulation will provide the basic information necessary for epigenetic engineering [34], and a valuable platform for potential applications of epigenetic engineering of plants towards enhanced tolerance to the environmental stresses. Therefore, deciphering the epigenetic mechanisms of gene regulation has become an important area of scientific investigations towards unraveling the mechanisms used by plants to tackle environmental stresses, survive under unfavorable conditions [24] [35]. Some of the plants (crop plants) have evolved to survive, reproduce, and produce edible (vegetative and/or reproductive) parts as food/feed of satisfactory quality to feed the burgeoning global animal and human populations [36]. The present review aims to emphasize the need to improve combined stress tolerance to several abiotic and biotic stresses in crop plants. For this purpose, the use of the package of practices, breeding approaches, biochemical, physiological, and/or molecular strategies are suggested to minimize the yield losses and improve the quality of products under field conditions.

\section{Abiotic Stresses Affect Productivity and Quality}

Most of the arable lands world over is prone to one or more of the abiotic stresses, which cause yield losses of up to $70 \%$ in many crops. According to an estimate, the ongoing climate change would enhance the intensity of the abiotic stresses which might more severely affect the productivity of crops that will have serious consequences on food security $[37,38]$. Extreme temperature, water stress (drought and flood), salinity, and heavy metal stress are some of the major environmental factors that affect growth, development, and yield of crop plants [38,39]. The concurrent and frequent occurrence of abiotic stresses is more destructive for food security. These are not only limited to abiotic environmental factors but also increase susceptibility to biotic stresses. Abiotic stress like drought enhances competition between weed and crop plants as several weeds show better water use efficiency compared to that of crops [40, 41]. The effects of combined stresses on crop plants are not always additive; it might be subtractive also, particularly when certain abiotic and biotic stress occur simultaneously, as the nature of the interaction between the stresses determines the outcome [10] $[42,43]$. This involves morpho-physio-biochemical interactions between the stresses. Abiotic stresses not only affect 
the productivity of the crop, but also affect the quality of the produce.

\subsection{Extreme temperature}

A gradual rise in the frequency and intensity of extreme temperatures are being observed [44]. Extreme temperature stresses like heat and freezing/cold/chilling stress have severe effects during critical stages of plant growth and development [45]. When the ambient temperature increases beyond a level, which causes damage to plant growth, it is known as heat stress. The deleterious effect of heat stress is a complex function of intensity, duration, and rate of increase in temperature, and a significant $\left(5-15^{\circ} \mathrm{C}\right) /$ quick increase in temperature is more deleterious. Heat stress affects the biochemical and physiological functions of the plant by modulating molecular mechanisms [46, 47]. For example, AtSUT2 is down-regulated under heat stress in Arabidopsis [48], and PtaSUT4 is up-regulated under heat stress in poplar [49] which is correlated with reduced sucrose transport from leaves. Similarly, OsSUT1 is down-regulated under heat stress in rice, and affect grain quality [50]. Higher temperature reduces germination of seeds and affects stand establishment of the crop. Moreover, the adverse effects of increased temperature vary with the duration and severity of the heat stress along with the developmental stage of the crop. Heat stress was reported to reduce the number of spikes/florets in rice [51]. Thus, high-temperature stress affects the yield of crop plants. The quality of the produce is also adversely affected by heat stress as it reduces starch and protein contents.

Low temperature/cold stress also affects biochemical and physiological activities in plants, and thus yield and quality of the produce. Lower temperature disturbs membrane structure, protoplasmic streaming, and cause electrolyte leakage/plasmolysis [52]. Freezing temperatures tress affects mineral acquisition, photosynthesis, respiration, and metabolism. Responses of plants to low-temperature stress are associated with the change in transcription of the genes associated with the production of several low molecular weight proteins.

\subsection{Water Stress}

Water stress includes its deficiency or excessive presence in the environment. Excessive water or flooding can be of two types, waterlogging (when water covers the root) or submergence (when water completely covers the plant, even aerial tissues). Both types interfere in oxygen availability to plant causing low-oxygen/hypoxia [53]. Flooding stress triggers significant changes in the molecular process, which help to coordinate morphological and physiological adaptations to the stress. In Arabidopsis, five $E R F$ (ethylene response factor) genes were identified to be the key regulators for flooding and hypoxia tolerance [54]. ERF-VII TF, SUB1A, is known to be a master regulator of submergence tolerance. A submergence-tolerance SUB1A gene expresses during the submergence condition only, and its transcript disappears quickly after the withdrawal of the flooding condition [55]. Studies demonstrate the involvement of physiological, genetic, epigenetic, and molecular mechanisms in providing flooding tolerance in plants [56].

On the contrary, drought stress involves a shortage of water availability for the plant which significantly affects growth, development, and yield of the crop. Drought can also be of two types: physical drought (deficiency of water due to its unavailability) and physiological drought (failure of the plant to take up water from the soil because of various physiological reasons like salinity, freezing, etc.) [57]. Under drought stress, humidity in the atmosphere is also very low, and the increased temperature makes the problem more severe. Co-occurrence of stresses, such as drought and heat stresses, is a common incident during the summer season. Moreover, the repetitive occurrence of abiotic stress, for example, the incidence of drought stress, is becoming a common feature due to global climate change. Furthermore, the occurrence of the contrasting stresses, like drought and flood stress appearing one after another in the same area or simultaneously in different areas, is becoming frequent. Combined stresses are more detrimental to the yield and quality of the produce. Therefore, understanding the regulatory mechanisms and how they protect plants from stresses has become vital to enhance the yield and quality of the produce in the changing climatic conditions. The modern advances in "omics" technologies provide momentum to the research in this area [58, 59, 60].

\subsection{Salt Stress}

Salinity stress appears due to increased content of salts in the soil, which mainly occurs because of a higher rate of evaporation/transpiration compared to the precipitation. Salinity stress is becoming one of the serious problems in several parts of the world, especially in the arid and semiarid regions. Salt stress is taking a serious dimension in the areas where saline-sodic water is being used for irrigation. It has been estimated that one-third of the food production of the world comes from irrigated lands, but $\sim 20 \%$ (about 45 million hectares) of the lands are affected by salinity stress which reduces $>50 \%$ of the potential yield of annual crops [25]. The damage further intensified by the synchronized action of multiple stresses including drought, and heat stress [61]. Some of the significant impacts of salt stress on crop plants include ionic toxicity and osmotic stress. Like other abiotic stresses, salt stress causes reactive oxygen species (ROS) generation that damages several biomolecules like lipids, proteins, and nucleic acids which alters redox homeostasis [26]. Salt stress has some adverse effects on cellular growth, membrane functions, and cytosolic metabolism. Ul- 
timately, it adversely affects the quantity and quality of the produce. Plants deploy different mechanisms to sense, respond, and adapt to salinity stress, including morpho-physiological, biochemical, epigenetic, and molecular mechanisms [29]. The profuse root system is important to provide salt stress tolerance to crop plants [62].

\subsection{Heavy Metal Stress}

Plants take up most of the nutrients from the soil for their growth and development. The increasing contamination of soil with heavy metals has become one of the important reasons for the loss in crop productivity [63]. Crops are frequently subjected to heavy metal toxicity due to irrigation with contaminated water and excessive application/use of chemical fertilizers/pesticides. Industrial waste disposal, burning of solid/liquid fuels, domestic garbage disposal, and other activities in the developing countries cause heavy metal contamination of soil and water. Some of the potentially toxic heavy metals like $\mathrm{Zn}, \mathrm{Fe}, \mathrm{Cu}$, $\mathrm{Co}$, Se, and $\mathrm{Ni}$ are essential microelements required for the optimal performance of crop plants. However, they become toxic when accumulated in excess in soil [64]. Certain non-essential elements like arsenate (As), cesium (Cs), lead ( $\mathrm{Pb}$ ), and cadmium (Cd) hamper the growth and productivity of crop plants when present soil [65]. More importantly, heavy metal contamination in the soil leads to the accumulation of these toxic metals in plant parts, resulting in increased risk to animal and human health [66]. Cd toxicity adversely affects cellular molecules, thereby growth of the plant, resulting in reduced leaf area, decreased shoot/root growth, and crop yield [67].

\section{Effects of Abiotic Stress on Plant Growth}

Growth and development of an organism are accomplished through enlargement division and differentiation of cells and involves ecological, genetic, physiological, biochemical, and morphological events and their complex interactions. Some of the important growth parameters in the assessment of crop growth include plant height, leaf area, rootgrowth, biomass production, etc. The plant growth depends on the environmental factors including nutrients and water supply, abiotic and biotic stresses. Cell growth is considered as one of the most stress-sensitive physiological processes because of the reduction in turgor pressure. Under severe drought, cell elongation in higher plants gets repressed due to the disruption of water movement from xylem to the surrounding elongating cells [68]. Under abiotic stress, the compromised mitotic cell division, cell elongation, and expansion result in decreased plant height, leaf area, biomass production, and finally reduced yield and quality of the produce [69, 70]. During water-deficit stress, a considerable decrease in root biomass can be seen [18]. Primary effects of abiotic stresses like drought and salinity are reduced germination of seeds and poor establishment of crop plants [69]. Drought stress combined with heat stress significantly affects nodule formation and activity; hence affects the biological nitrogen fixation and yield of the crop. Siczek and Lipiec [71] observed that mulching considerably improved soil moisture content which resulted in improved nodule formation, nitrogenase activity, symbiotic nitrogen fixation, and the crop yield.

Interestingly, some positive effects associated with water stress may also be observed. Water-deficit stress encourages secondary metabolite production, thus potentially increasing plant immunity and the level of the compounds involved in improving quality, taste, and the health benefits of certain plant products. This is also considered as one of the factors behind stress memory (in addition to epigenetic memory), and stress priming. The role of drought in the production of secondary metabolites in some fruit crops is of vital importance.ABA has been known as a key chemical stress-signal from roottoshoot [72]. During abiotic stresses, ABA is produced by roots and transported through the xylem to the shoot where it affects leaf expansion and promotes stomatal closure to regulate water potential and nutrient status in leaves. ABA biosynthesis gets stimulated by a decrease in soil water and plant turgor. A study on wheat under water-deficit stress by Yang et al. [73] suggested that ABA and cytokinins are involved in controlling senescence and carbon remobilization in plants. Another study on wheat suggests that grain-filling in wheat gets improved due to the increased ratio of ABA to ethylene [74]. In general, stomatal regulation is considered as the first step to deal with the drought stress by retaining enough cell turgor to manage cellular metabolism in plants. However, little is known about how shoot-subjected stresses affect root growth.

\subsection{Effect of Abiotic Stress on Photosynthesis}

Photosynthesis is adversely affected by environmental stresses. Photosystem II (PS II) is more vulnerable to heat stress than drought stress due to exclusion of PS II in thylakoid membranes resulting in the interruption of rubisco activase [75]. The effects of the abiotic stress also vary in $C_{3}$ (e.g., wheat) and $C_{4}$ (e.g., maize) plants. $C_{4}$ plants are considered to be more sensitive to drought stress, probably due to stomatal closure and decrease in the activity of the photosynthetic enzyme [76]. However, the effect of heat stress on the photosynthetic capability is stronger in the $C_{3}$ plant compared to that in the $\mathrm{C}_{4}$ plant due to the diverse energy distribution and actions of carbon metabolic enzymes, particularly rubisco [77]. Regardless of any change in stomatal conductance, abiotic stress reduces photosynthetic activity in the plant under stress [78]. A decrease in the photosynthetic activity under drought and heat stresses are frequently attributed to lowered internal $\mathrm{CO}_{2}$ concentration, inhibition of enzymes involved in photosynthesis [79]. Therefore, 
plants decrease their growth as an adaptive response to the stress, rather than as a consequence of resource limitation [12].

Under abiotic stresses, excessive production of ROS, such as singlet oxygen, superoxide radical, hydrogen peroxide, hydroxyl radical, cause membrane injuries [80], protein degradation [58], enzyme inactivation, and thus give rise to the oxidative stress [79]. Denaturation of proteins/enzymes, increased fluidity of membrane lipids, inactivation of enzymes, reduced production and degradation of proteins, disturbed membrane integrity, and damage to DNA are some of the cellular injuries caused by the abiotic stresses [23] [81] (Figure 1). Heat stress also affects ion flux leading to the biosynthesis of toxic compounds and ROS. Prolonged exposure to heat stress causes a decrease in chlorophyll content, increased amylolytic activity, disintegration of thylakoid, and disruption of assimilate transport. Even moderately higher temperatures for a longer period or very high temperatures for a short period may cause severe cellular injury or death of the plants [82]. To minimize the cellular damage, the affected plant produces enzymes, phenolic compounds, flavonoids, anthocyanins, lignins, and other molecules to fight against the deleterious effects and to manage the oxidative stress [79] [83]. Expression of heat shock proteins is an important strategy of plants to improve heat tolerance (thermo-tolerance) through maintaining photosynthesis, water, and nutrient use efficiency [84], and cellular membrane stability [85]. Thus, abiotic stress affects photosynthesis and partitioning of the photosynthate. This also affects the harvest index due to the disturbed transport of photosynthate to the grain.

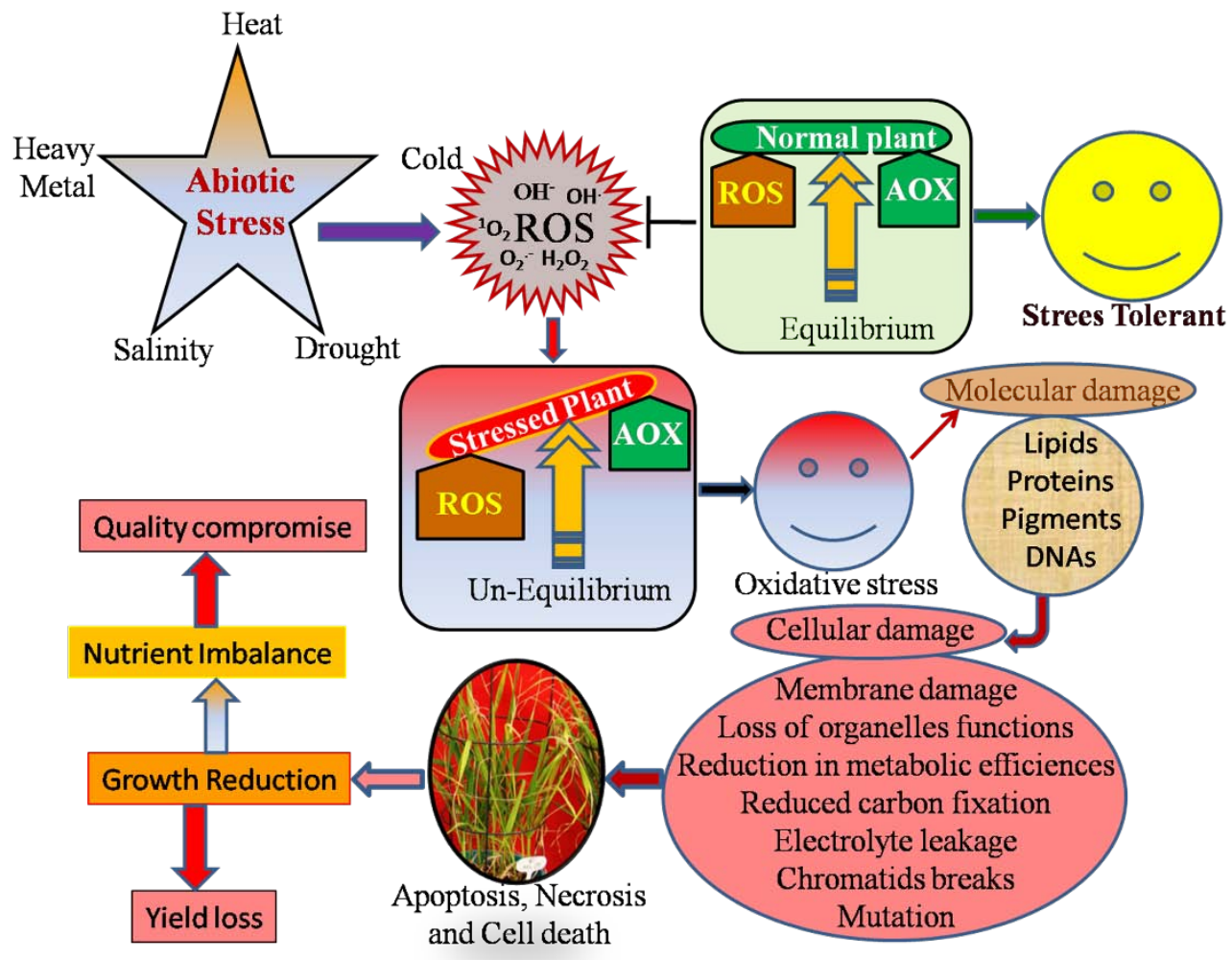

Figure 1. Effects of abiotic stresses on plants productivity, yield and quality of the produce.

Reduced activity of acid invertase can arrest the development of reproductive tissues due to improper phloem unloading. Besides, abiotic stresses, particularly drought stress, may inhibit important functions of vacuolar invertase-mediated sucrose hydrolysis and modulation of osmotic potential. In maize, low invertase activity in the young ovaries lowered the ratio of hexoses to sucrose under drought stress. This resulted in reduced cell division in the developing embryo/endosperm affecting the sink intensity and abortion of the embryo [86]. Abiotic stresses, particularly heat stress, significantly affect the plants growing in tropical and subtropical climates. The increasing temperature may alter the geographical distribution, growing duration/season of crops due to changes in the appearance of threshold temperature for proper germination of seeds (the start of the season) and that for the maturity of the crop [87].

\subsection{Effects of Abiotic Stress on Productivity and Yield}

Reduced shoot growth, a decline in the number of tillers in response to water-deficit is considered as a strategy of the plant to reduce the expenditure of water during the stress [88]. It has been reported that early heading in response to 
heat stress is advantageous in retaining more green leaves at anthesis, leading to the minimized reduction in yield [57]. Studies on different plant species have indicated that high temperature (heat stress) is more harmful at the reproductive/gametogenesis stage of crop growth [82]. Heat stress significantly disrupts the anatomy not only at the tissue and cellular levels but also at the sub-cellular levels. At the sub-cellular level, the major disruptions include deformation of the chloroplast, swelling of stromal lamellae, lumpiness of vacuoles, which result in the altered structural organization of thylakoids and formation of antenna depleted PSII and thereby reduce photosynthetic and respiratory activities [89]. Ultimately, all these changes due to abiotic stress may lead to poor plant growth and productivity of crop plants.

Yield reduction due to drought stress has been reported in many crop species, which depends on the severity and duration of the stress. Water plays an important role in the mineral nutrition of plants since most of the nutrients from the soil are mobilized with the movement of water. Disturbance in the $\mathrm{Na}^{+} / \mathrm{K}^{+}$ratio results in membrane damage, poor membrane stability, and disturbed ionic homeostasis [90]. Water-deficit stress may cause about a $50 \%$ decrease in the $\mathrm{Ca}^{2+}$ concentration which is important for in maintaining the integrity of cell membranes and other structures in shoot and root. Besides, water-deficit stress affects nutrient metabolism by inhibiting activities of nitrate reductase and glutamine synthetase involved in the intracellular assimilation of ammonia into organic compounds [91]. In barley, drought stress caused a decrease in the grain yield by reducing the number of tillers, spikes, and grains per plant as well as the grain weight. In maize, the stress decreases the yield by delayed silking, thereby increasing the anthesis to the silking period [92]. After flowering, drought stress had a lesser effect on grain filling in wheat, but it shortened the maturity (fertilization to maturity) period [93]. Drought stress during reproductive growth reduced cotton lint yield due to reduced boll formation and greater boll abortion [94].

The biological yield of plants under unfavourable environmental conditions is affected due to the inefficient physiological and biochemical activities. During grain filling in cereals and pulses, four enzymes play critical roles which include sucrose synthase, adenosine diphosphate-glucose-pyrophosphorylase, starch synthase, and starch branching enzyme. While reduced sucrose synthase activity results in a decreased rate of grain development, inactivation of adenosine diphosphate-glucose-pyrophosphorylase in wheat was reported to interrupt the growth due to drought stress [95]. Heat stress during grain filling may alter nitrogen supply/concentration in grain legumes [18], reduced starch, protein, and oil contents in wheat and maize [96, 97] which affect not only the yield but baking quality of wheat flour.

\subsection{Effect of Abiotic Stress on Quality of Produce}

Providing food to the burgeon global population is a preliminary challenge today; however, a major challenge being faced is to produce safe and nutritious food under the increasingly unfavorable environmental conditions [98, 99]. Global climate change is expected to further worsen climatic conditions which will not only affect the productivity of the crops but the quality of the produces also. Therefore, we must not only bother about producing sufficient food to feed the burgeoning global population but also to produce nutritious foods to provide a healthy diet [99].

An increase in protein content at the grain formation stage has been reported by some of the workers which were explained based on an increase in the amount of starch in response to the abiotic stress. In wheat, decreased quality of gluten content, glutenin content, gliadin content, grain hardness, but increased protein content-indexes in wheat under drought and salt stress was reported [100, 101]. Hoegy et al. [102] reported the effect of increased soil temperature $\left(2.5^{\circ} \mathrm{C}\right)$ causing increased protein content, particularly the content of aspartate, glycine, alanine, arginine, valine, and tryptophan in barley. The effect of heat stress on yield and grain quality of wheat was studied 18 days after anthesis, and it was found that the stress reduced grain mass by $23 \%$. Not only this, but the stress also reduced nitrogen content by $16 \%$ in the grains. But the decrease was less than the reduction in grain yield; the net effect ultimately turned into an increase in protein content in the grains. Interestingly, a significant increase in the number of proteins in the filling grain was observed shortly after the withdrawal of the stress [103]. Dwivedi et al. [104] reported that mid-season drought had no effect on protein content in peanut, but the end-season drought significantly increased the total protein content. In the case of rice, high temperatures during the early grain filling stage increased the accumulation of storage proteins but decreased the accumulation of prolamins at maturity [105].

In soybean seeds, carbohydrate composition considerably changes with increasing day/night temperature $\left(18 / 13^{\circ} \mathrm{C}\right.$ to $\left.33 / 28^{\circ} \mathrm{C}\right)$ [106]. Higher temperature $\left(37 / 17^{\circ} \mathrm{C}\right)$ during flowering/grain filling caused a significant reduction in the duration for starch accumulation in wheat, this duration is generally longer in the plants grown under normal $\left(24 / 17^{\circ} \mathrm{C}\right)$ temperature. Heat stress $\left(37 / 28^{\circ} \mathrm{C}\right)$ was observed to shorten the starch accumulation period by 21 days compared to that in the control plant, which also increases the proportion of A-type starch granules but decreases the B-type granules [107]. The impact of abiotic stresses on non-structural carbohydrates is important in two aspects that determine the quality of the produce. Quantity, as well as quality of carbohydrates, are important in the crops which are used in food processing, fermentation, etc. The major factor contributing to the reduced starch concentration appears to be the inhibition of starch synthase enzyme in the maturing grain, resulting in the impeded conversion of sugars to starch. Increased starch concentration was observed in potato tubers under salinity and heat stress [108]. In contrast, increased sucrose 
concentration, but the reduced starch formation was observed under drought stress in potato [109]. Interestingly, abiotic stresses were also found to affect the amylose/amylopectin ratio in the starch of cereal grain and tuber. Water-deficit stress during the grain filling decreased the amylose component of wheat starch, which was explained with the inhibition of granule bound starch synthase (GBSS) activity (an enzyme involved in amylose synthesis) [110]. In contrast, high temperatures led to an increase in the proportion of amylose in wheat [111], potatoes [112], and sweet potatoes [113]. These changes in heat-induced starch composition might also be attributed to the altered activity of the enzyme GBSS [113].

Oil content in soybean was found to be positively correlated with increased temperature $\left(25^{\circ} \mathrm{C}\right.$ to $\left.36^{\circ} \mathrm{C}\right)$ [106]. Thomas et al. [114] investigated the effects of heat stress on the composition of soybean seeds and found the oil content to be highest at $32 / 22^{\circ} \mathrm{C}$ day/night temperature, and a decreasing pattern with further increase in the temperature. Oleic acid content increased with the increasing temperature, whereas linolenic acid content decreased. A similar result was also observed in sunflower by Izquierdo et al. [115]. Heat tress has a general effect on reducing the amounts of accumulated lipids, particularly non-polar lipids. Besides, unexpected qualitative changes (such as the increased apparent conversion of oleate to linoleate) were observed at higher temperatures [116]. Such alterations may significantly influence the milling properties of wheat and baking quality of the flour. Heat stress (especially when coupled with drought stress) is often associated with the production of smaller, more fibrous leaves, which usually affect nutritional quality like decreased $\mathrm{N}$ and increased tannins and phenols [117]. A significant decrease in the proportion of PUFA was observed under drought stress in the oil fractions of sunflower [118], groundnut [103], under salt stress in sunflower [119], and under heat stress in soybean [120]. In many of the cases, the observed decrease in PUFA (especially linoleic acid) was consistent with an increase in the proportion of oleic acid [121].

The effect of abiotic stress on the dietary fiber content of wheat and barley was reported to decrease $\beta$-glucan content. Studies on three wheat cultivars under heat, drought, and the combined effects of heat and drought were found to cause decreased $\beta$-glucan content in grains which is associated with the decrease in the ratio of short to long-chain gluco-oligosaccharides [122]. As water plays an important role in mineral mobilization in plants, drought stress reduces the uptake of $\mathrm{Fe}, \mathrm{Zn}$, and $\mathrm{Cu}$ fromthe soil, resulting in decreased concentration of these minerals ingrain [123]. However, severe water-deficit stress was reported to significantly increase Ca (28\%),Mg (11\%), Cu (18\%), and Zn (33\%) content in maize [124].

\section{Conclusions}

Reduction in biomass production by crop plants is the most apparent and widely recognized effect of abiotic stresses, which results in quantitative and qualitative yield losses. The need of the day is not only to focus on increasing the yield but the quality of the product also, through breeding programs and agronomic practices to mitigate the effects of abiotic stresses. Reduced biomass production is often the result of reduced photosynthetic carbon assimilation; hence the concentration of many other components tends to increase, leading to higher crude protein and mineral concentrations. Stress-induced stomatal closure decreased transpiration rate, and impaired photosynthesis activity (particularly due to the effects on PS II and photosynthetic enzymes) lead to early crop maturity and poor productivity. In the case of leguminous plants, abiotic stresses decrease nodule formation and nitrogen fixation activities. Other responses include the accumulation of certain compounds of low molecular mass (like proline). While biochemical and physiological effects of abiotic stresses on crop yield are relatively understood, further research on their effects on the quality of the produce is needed. Molecular knowledge of the responses to abiotic stress is likely to pave the way for tailor making the crop plants to withstand the climatic changes and provide satisfactory economic yields. However, a multi-disciplinary research effort would be required to integrate genotypic, phenotypic, proteomic, transcriptomic, epigenetic and metabolomics data to understand the networks that lead to the quality attributes. This would help in devising better strategies to designclimate-resilient crop plants to cope with the effects of global climate change.

The views expressed herein are those of the author only, and these may not necessarily be the views of the institution/organization the author is associated with.

\section{References}

[1] Zandalinas, et al. (2018). Plant adaptations to the combination of drought and high temperatures. Physiologia Plantarum, 162, pp. 2-12. doi: 10.1111/ppl.12540.

[2] Mittler, R. (2006). Abiotic stress, the field environment and stress combination. Trends in Plant Science, 11, pp. 15-19. doi: 10.1016/j.tplants.2005. 11.002.

[3] Prasad, et al. (2011). Independent and combined effects of high temperature and drought stress during grain filling on plant yield and chloroplast EF-Tu expression in spring wheat. Journal of Agronomy and Crop Science, 197, pp. 430-441.

[4] Mahalingam, R. (2015). Consideration of combined stress: a crucial paradigm for improving multiple stress tolerance in plants. 
In: Combined Stresses in Plants. Springer International Publishing, pp. 1-25. doi: 10.1007/978-3-319-07899-1_1.

[5] Pandey, et al. (2017). Impact of combined abiotic and biotic stresses on plant growth and avenues for crop improvement by exploiting physio-morphological traits. Frontiers in Plant Science, 8, 537.

[6] Coakley, et al. (1999). Climate change and plant disease management. Annual Review of Phytopathology, 37, pp. 399-426.

[7] Scherm, H. \& Coakley, S. M. (2003). Plant pathogens in a changing world. Australia Plant Pathology, 32, pp. 157-165. doi: 10.1071/AP03015.

[8] Ziska, et al. (2010). Evaluation of competitive ability between cultivated and red weedy rice as a function of recent and projected increases in atmospheric $\mathrm{CO}_{2}$. Agronomy Journal, 102, pp. 118-123. doi: 10.2134/agronj2009.0205.

[9] Peters, et al. (2014). Impact of climate change on weeds in agriculture: a review. Agronomy for Sustainable Development, 34, pp. 707-721. doi: 10.1007/s13593-014-0245-2.

[10] Pandey, et al. (2015). Impact of concurrent drought stress and pathogen infection on plants. In: Combined Stresses in Plants, ed. R. Mahalingam, Springer International Publishing, pp. 203-222.

[11] Dreesen, et al. (2012). Summer heat and drought extremes trigger unexpected changes in productivity of a temperate annual/biannual plant community. Environmental and Experimental Botany, 79, pp. 21-30.

[12] Rollins, et al. (2013). Leaf proteome alterations in the context of physiological and morphological responses to drought and heat stress in barley (Hordeum vulgare L.). Journal of Experimental Botany, 64, pp. 3201-3212.

[13] Sehgal, et al. (2017). Effects of drought, heat and their interaction on the growth, yield and photosynthetic function of lentil (Lens culinaris Medikus) genotypes varying in heat and drought sensitivity. Frontiers in Plant Science, 8, 1776. doi: 10.3389/fpls.2017.01776.

[14] Sehgal, et al. (2018). Drought or/and heat-stress effects on seed filling in food crops: Impacts on functional biochemistry, seed yields, and nutritional quality. Frontiers in Plant Science, 9, 1705.

[15] Trenberth, K. E. (2001). Changes in precipitation with climate change. Climate Research, 47, pp. 123-138.

[16] Vadez, et al. (2012b). Modelling possible benefits of root related traits to enhance terminal drought adaptation of chickpea. Field Crops Research, 137, pp. 108-115.

[17] Nadeem, et al. (2019). Research progress and perspective on drought stress in legumes: A review. International Journal of Molecular Science, 20, pp. 2541.

[18] Sekhon, et al. (2010). Water use efficiency under stress environments. In: Climate Change and Management of Cool Season Grain Legume Crops. Springer Netherlands, pp. 207-227.

[19] Jedmowski, et al. (2015). Impact of drought, heat, and their combination on chlorophyll fluorescence and yield of wild barley (Hordeumspontaneum). Journal of Botany, 9, doi: 10.1155/2015/12

[20] Farooq, et al. (2012). Drought stress in plants: an overview. In: Plant Responses to Drought Stress. Springer Berlin Heidelberg, pp. 1-33.

[21] Toscano, et al. (2019). Effect of preharvest abiotic stresses on the accumulation of bioactive compounds in horticultural produce. Frontiers in Plant Science, 10, 1212.

[22] Rouphael, et al. (2018). Salinity as eustressor for enhancing quality of vegetables. Scientia Horticulturae, 234, pp. 361-369. doi:10.1016/j.scienta.2018.02.048.

[23] Singh, et al. (2015). Induced defence responses of contrasting bread wheat genotypes under differential salt stress imposition. Indian Journal of Biochemistry and Biophysics, 52, pp. 75-85.

[24] Kumar, S. \& Singh, A. (2016). Epigenetic regulation of abiotic stress tolerance in plants. Advances in Plants Agriculture Research, 5, e00179. doi: 10.15406/apar.2016.05.00179.

[25] Singh, et al. (2018). Biochemical, physiological, and molecular approaches for improving salt tolerance in crop plants-a review. In: Engineering Practices for Management of Soil Salinity, CRC Press, USA. pp. 159-208.

[26] Awana, et al. (2019). Insights into salt stress-induced biochemical, molecular and epigenetic regulation of spatial responses in Pigeonpea (Cajanus cajan L.). Journal of Plant Growth Regulation, 38, pp. 1-17.

[27] Kalia, et al. (2016). Recent advances in understanding the role of growth regulators in plant growth and development in vitro-II: non-conventional growth regulators. Indian Forester 142, pp. 524-535.

[28] Kumar, et al. (2017a). Physiological, biochemical, epigenetic and molecular analyses of wheat (Triticum aestivum) genotypes with contrasting salt tolerance. Frontiers in Plant Science 8, 1151. dpi: 10.3389/fpls.2017.01151.

[29] Kumar, S., Singh, A. K., \& Mohapatra, T. (2017c). Epigenetics: history, present status and future perspective. Indian Journal of Genetics and Plant Breeding, 77, pp. 445-463. doi: 10.5958/0975-6906.2017.00061.X.

[30] Kumar, S. (2018c). Epigenetic memory of stress responses in plants. Journal of Phytochemistry and Biochemistry, 2, e102.

[31] Chinnusamy, V. \& Zhu, J. K. (2009). Epigenetic regulation of stress responses in plants. Current Opinion in Plant Biology, 12, pp. 133-139. 
[32] Kumar, S. (2017). Epigenetic control of apomixis: a new perspective of an old enigma. Advances in Plants and Agriculture Research, 7, e00243. doi: 10.15406/apar.2017.07.00243.

[33] Wang, et al. (2016). The cytosolic Fe-S cluster assembly component MET18 is required for the full enzymatic activity of ROS1 in active DNA demethylation. Scientific Reports, 6, e26443.

[34] Li, et al. (2018). Active DNA demethylation: mechanism and role in plant development. Plant Cell Reports, 37, pp. 1-9. doi: 10.1007/s00299-017-2215-z.

[35] Rathore, et al. (2020). Retro-element Gypsy-163 is differentially methylated in reproductive tissues of apomictic and sexual plants of Cenchrus ciliaris. Frontiers in Genetics, 11, 795.

[36] Kumar, S. (2018b). Environmental stress, food safety, and global health: biochemical, genetic and epigenetic perspectives. Medical Safety Global Health, 7, e145.

[37] Tigchelaar, et al. (2018). Future warming increases probability of globally synchronized maize production shocks. Proceedings of National Academy of Science, 115, pp. 6644-6649. doi: 10.1073/pnas.1718031115.

[38] Zörb, et al. (2019). Salinity and crop yield. Plant Biology, 21, pp. 31-38. doi: 10.1111/plb.12884.

[39] Vaughan, et al. (2018). The effects of climate change associated abiotic stresses on maize phytochemical defenses. Phytochemistry Reviews, 17, pp. 37-49. doi: 10.1007/s11101-017-9508-2.

[40] Ziska, et al. (2010). Evaluation of competitive ability between cultivated and red weedy rice as a function of recent and projected increases in atmospheric $\mathrm{CO}_{2}$. Agronomy Journal, 102, pp. 118-123. doi: 10.2134/ agronj2009.0205.

[41] Valerio, et al. (2013). The role of water availability on weed-crop interactions in processing tomato for southern Italy. Acta Agriculturae Scandinavica, Section B, 63, pp. 62-68. doi: 10.1080/09064710.2012.715184.

[42] Atkinson, N. J., Lilley, C. J., \& Urwin, P. E. (2013). Identification of genes involved in the response to simultaneouss biotic and abiotic stress. Plant Physiology, 162, pp. 2028-2041. doi: 10.1104/pp.113.222372.

[43] Ramu, et al. (2016). Transcriptome analysis of sunflower genotypes with contrasting oxidative stress tolerance reveals individual- and combined-biotic and abiotic stress tolerance mechanisms. PLoS ONE, 11, e0157522. doi: 10.1371/journal.pone.0157522.

[44] IPCC. (2014). Climate change synthesis report contribution of working groups I. II and III to the fifth assessment report of the intergovernmental panel on climate change. IPCC, Geneva.

[45] Zhou, et al. (2018). Phenotyping of faba beans (Viciafaba L.) under cold and heat stresses using chlorophyll fluorescence. Euphytica, 214, 68. doi: 10.1007/s10681-018-2154-y.

[46] Muhlemann, et al. (2018). Flavonols control pollen tube growth and integrity by regulating ROS homeostasis during high-temperature stress. Proceedings of National Academy of Science, 115, pp. E11188-E11197. doi: 10.1073/pnas.1811492115.

[47] Takahashi, F., \& Shinozaki, K. (2019). Long-distance signaling in plant stress response. Current Opinion in Plant Biology, 47, 106-111. doi: 10.1016/j.pbi.2018.10.006.

[48] Xu, et al. (2018). Regulation of sucrose transporters and phloem loading in response to environmental cues. Plant Physiology, 176, pp. 930-945. doi: 10.1104/pp.17.01088.

[49] Xue, et al. (2016). Drought response transcriptomes are altered in poplar with reduced tonoplast sucrose transporter expression. Scientific Reports, 6, 33655. doi: 10.1038/srep33655.

[50] Miyazaki, et al. (2013). Assimilate translocation and expression of sucrose transporter, OsSUT1, contribute to high-performance ripening under heat stress in the heat-tolerant rice cultivar Genkitsukushi. Journal of Plant Physiology, 170, 1579-1584. doi: 10.1016/j.jplph.2013.06.011.

[51] Fahad, et al. (2016). Exogenously applied plant growth regulators affect heat-stressed rice pollens. Journal of Agronomy and Crop Science, 202, pp. 139-150. doi: 10.1111/jac.12148.

[52] Yadav, et al. (2017). Effect of abiotic stress on crops. In: Sustainable Crop Production Eds. Mirza Hasanuzzaman, et al., Intech Open, doi: 10.5772/intechopen.88434.

[53] Sasidharan, et al. (2017). Community recommendations on terminology and procedures used in flooding and low oxygen stress research. New Phytologists, 214, pp. 1403-1407. doi: 10.1111/nph.14519.

[54] Gasch, et al. (2016). Redundant ERF-VII transcription factors bind to an evolutionarily conserved Cis-motif to regulate hypoxia-responsive gene expression in Arabidopsis. Plant Cell, 28, pp. 160-180. doi: 10.1105/tpc.15.00866.

[55] Fukao, T., Yeung, E., \& Bailey-Serres, J. (2011). The submergence tolerance regulator SUB1A mediates crosstalk between submergence and drought tolerance in rice. Plant Cell, 23, pp. 412-427. doi: 10.1105/tpc.110.080325.

[56] Fukao, et al. (2019). Submergence and waterlogging stress in plants: A review highlighting research opportunities and understudied aspects. Frontiers in Plant Science, 10, doi: 10.3389/fpls.2019.00340.

[57] Vadez, et al. (2012). Adaptation of grain legumes to climate change: a review. Agronomy and Sustainable Development, 32, pp. $31-44$. 
[58] Samota, et al. (2017). Elicitor-induced biochemical and molecular manifestations to improve drought tolerance in rice (Oryza sativa L.) through seed-priming. Frontiers in plant science, 8, 934.

[59] Kumar, S. (2018a). Epigenomics of plant responses to environmental stress. Epigenomes, 2, pp. 1-17. doi: 10.3390/epigenomes2010006.

[60] Kumar, S., Chinnusamy, V., \& Mohapatra, T. (2018). Epigenetics of modified DNA bases: 5-methylcytosine and beyond. Frontiers in Genetics, 9, pp. 1-14.

[61] Huang, et al. (2019). Increasing aridity affects soil archaeal communities by mediating soil niches in semi-arid regions. Science of the Total Environment, 647, pp. 699-707. doi: 10.1016/j.scitotenv.2018.07.305.

[62] Isayenkov, S., \& Maathuis, F. J. M. (2019). Plant salinity stress; many unanswered questions remain. Frontiers in Plant Science, 10, pp. 1-11. doi: 10.3389/fpls.2019.00080.

[63] Proshad, et al. (2018). Heavy metal toxicity in agricultural soil due to rapid industrialization in Bangladesh: a review. International Journal of Advances in Geoscience, 6, pp. 83-88.

[64] Narendrula-Kotha, et al. (2019). Metal toxicity and resistance in plants and microorganisms in terrestrial ecosystems. In: Reviews of Environmental Contamination and Toxicology, Switzerland: Springer, 249, pp. 1-27. doi: 10.1007/398_2018_22.

[65] Khalid, et al. (2018). A review of environmental contamination and health risk assessment of wastewater use for crop irrigation with a focus on low and high-income countries. International Journal of Environmental Research and Public Health, 15 , p. 895. doi: 10.3390/ijerph15050895.

[66] Couto, et al. (2018). Should heavy metals be monitored in foods derived from soils fertilized with animal waste? Frontiers in Plant Science, 9, 732. doi: 10.3389/fpls.2018.00732.

[67] Shah, et al. (2019). Cadmium-Induced Anatomical Abnormalities in Plants. In: Cadmium Toxicity and Tolerance in Plants, Academic Press Elsevier, pp. 111-139. doi: 10.1016/B978-0-12-814864-8.00005-X.

[68] Nonami, H. (1998). Plant water relations and control of cell elongation at low water potentials. Journal of Plant Research, 111, pp. 373-382.

[69] Kaya, et al. (2006). Seed treatments to overcome salt and drought stress during germination in sunflower (Helianthus annuusL.). European Journal of Agronomy, 24, pp. 291-295.

[70] Hussain, et al. (2008). Improving drought tolerance by exogenous application of glycinebetaine and salicylic acid in sunflower. Journal of Agronomy and Crop Science, 194, pp. 193-199.

[71] Siczek, A. \& Lipiec, J. (2011). Soybean nodulation and nitrogen fixation in response to soil compaction and surface straw mulching. Soil and Tillage Research, 114, pp. 50-56.

[72] Schachtman, D. P. \& Goodger, J. Q. (2008). Chemical root to shoot signaling under drought. Trends in Plant Science, 13, pp. 281-287.

[73] Yang, et al. (2003). Involvement of abscisic acid and cytokinins in the senescence and remobilization of carbon reserves in wheat subjected to water stress during grain filling. Plant, Cell and Environment, 26, pp. 1621-1631.

[74] Yang, et al. (2006). Abscisic acid and ethylene interact in wheat grains in response to soil drying during grain filling. New Phytologists, 171, pp. 293-303.

[75] Prasad, et al. (2008). Impacts of drought and/or heat stress on physiological, developmental, growth, and yield processes of crop plants. In: Response of Crops to Limited Water: Understanding and Modeling Water Stress Effects on Plant Growth Processes. Advances in Agricultural Systems Modeling Series 1. pp. 301-355.

[76] Alfonso, S. U. \& Brüggemann, W. (2012). Photosynthetic responses of a $\mathrm{C}_{3}$ and three $\mathrm{C}_{4}$ species of the genus Panicum with different metabolic subtypes to drought stress. Photosynthesis Research, 112, pp. 175-191.

[77] Salvucci, M. E. \& Crafts-Brandner, S. J. (2004). Relationship between the heat tolerance of photosynthesis and the thermal stability of Rubisco activase in plants from contrasting thermal environments. Plant Physiology, 134, pp. 1460-1470.

[78] Ashraf, M. \& Harris, P. J. C. (2013). Photosynthesis under stressful environments: an overview. Photosynthetica 51, pp. 163-190.

[79] Zlatev, Z. \& Lidon, F. C. (2012). An overview on drought induced changes in plant growth, water relations and photosynthesis. Emirates Journal of Food and Agriculture, 24, 57.

[80] Kumar, et al. (2015). Sodium chloride-induced spatial and temporal manifestation in membrane stability index and protein profiles of contrasting wheat (Triticumaestivum L.) genotypes under salt stress. Indian Journal of Plant Physiology, 20, pp. 271-275. doi: 10.1007/s40502-015-0157-4 2015.

[81] Kumar, et al. (2017b). Salt-induced tissue-specific cytosine methylation downregulates expression of $H K T$ genes in contrasting wheat (Triticum aestivum L.) genotypes. DNA and Cell Biology 36, pp. 283-394. doi: 10.1089/dna.2016.3505.

[82] Wahid, et al. (2007). Heat tolerance in plants: an overview. Environmental and Experimental Botany, 61, pp. $199-223$.

[83] Wahid, A. \& Close, T. J. (2007). Expression of dehydrins under heat stress and their relationship with water relations of sugarcane leaves. Biologia Plantarum, 51, pp. 104-109. 
[84] Camejo, et al. (2005). High temperature effects on photosynthetic activity of two tomato cultivars with different heat susceptibility. Journal of Plant Physiology, 162, pp. 281-289.

[85] Ahn, Y. J. \& Zimmerman, J. (2006). Introduction of the carrot HSP17.7 into potato (Solanum tuberosum L.) enhances cellular membrane stability and tuberization in vitro. Plant, Cell and Environment, 29, pp. 95-104.

[86] Andersen, et al. (2002). Soluble invertase expression is an early target of drought stress during the critical, abortion-sensitive phase of young ovary development in maize. Plant Physiology 130, pp. 591-604.

[87] Porter, J. R. (2005). Rising temperatures are likely to reduce crop yields. Nature, 436, pp. 174-174.

[88] El Soda, et al. (2010). Stability parameter and genotype mean estimates for drought stress effects on root and shoot growth of wild barley pre-introgression lines. Molecular Breeding, 26, pp. 583-593.

[89] Zhang, et al. (2005). Effect of temperature acclimation pretreatment on the ultra structure of mesophyll cells in young grape plants (Vitis vinifera) under cross temperature stresses. Journal of Integrative Plant Biololgy, 47, pp. 959-970.

[90] Abbassi, et al. (2014). Exogenous potassium differentially mitigates salt stress in tolerant and sensitive maize hybrids. Pakistan Journal of Botany, 46, pp. 135-146.

[91] Rizhysky, et al. (2004). When defense pathways collide: The response of Arabidopsis to a combination of drought and heat stress. Plant Physiology, 134, pp. 1683-1696.

[92] Cattivelli, et al. (2008). Drought tolerance improvement in crop plants: an integrated view from breeding to genomics. Field Crops Research, 105, pp. 1-14.

[93] Wardlaw, I. F. \& Willenbrink, J. (2000). Mobilization of fructan reserves and changes in enzyme activities in wheat stems correlate with water stress during kernel filling. New Phytologists, 148, pp. 413-422.

[94] Pettigrew, W. T. (2004). Moisture deficit effects on cotton lint yield, yield components, and boll distribution. Agronomy Journal, 96, pp. 377-383.

[95] Ahmadi, A. \& Baker, D. A. (2001). The effect of water stress on grain filling processes in wheat. The Journal of Agricultural Science, 136, pp. 257-269.

[96] Wilhelm, I. (1999). Crop physiology and metabolism. Crop Science, 39, pp. 1733-1741.

[97] Wardlaw, et al. (2002). Contrasting effects of chronic heat stress and heat shock on kernel weight and flour quality in wheat. Functional Plant Biology, 29, pp. 25-34.

[98] Kumar, S. (2012). Biopesticides: a need for food and environmental safety. Journal of Biofertilizers and Biopesticides, 3 , e107.

[99] Kumar, S. \& Krishnan, V. (2017). Phytochemistry and functional food: the needs of healthy life. Journal of Phytochemistry and Biochemistry, 1, e103.

[100] Eivazi, et al. (2006). Effect of drought and salinity stress on quality related traits in wheat (Triticum aestivum L.) cultivar. Iranian Journal of Crop Science, 7, pp. 252-267.

[101] Vafa, et al. (2014). The effect of drought stress on grain yield, yield components and protein content of Durum wheat cultivars in Ilam Province, Iran. International Journal of Agricultural and Biosystems Engineering, 8, pp. 631-636.

[102] Hoegy, et al. (2013). Impacts of temperature increase and change in precipitation pattern on crop yield and yield quality of barley. Food Chemistry, 136, pp. 1470-1477.

[103] Triboï, et al. (2003). Environmentally-induced changes in protein composition in developing grains of wheat are related to changes in total protein content. Journal of Experimental Botany, 54, pp. 1731-1742.

[104] Dwivedi, et al. (1996). Effect of drought on oil, fatty acids and protein contents of groundnut (Arachis hypogaea L.) seeds. Field Crops Research 48, pp. 125-133.

[105] Lin, et al. (2010). Influence of high temperature during grain filling on the accumulation of storage proteins and grain quality in rice (Oryza sativa L.). Food Chemistry, 58, pp. 10545-10552.

[106] Wolf, et al. (1982). Effect of temperature on soybean seed constituents: oil, protein, moisture, fatty acids, amino acids and sugars. Journal of the American Oil Chemists' Society, 59, pp. 230-232.

[107] Barnabás, et al. (2008). The effect of drought and heat stress on reproductive processes in cereals. Plant, Cell and Environment, 31, pp. 11-38.

[108] Silva, et al. (2001). Microtuberization of Andean potato species (Solanum spp.) as affected by salinity. Scientia Horticulturae, 89, pp. 91-101.

[109] Bethke, et al. (2009). Tuber water and pressure potentials decrease and sucrose contents increase in response to moderate drought and heat stress. American Journal of Potato Research, 86, p. 519.

[110] Singh, et al. (2008). Effect of water stress at different stages of grain development on the characteristics of starch and protein of different wheat varieties. Food Chemistry, 108, pp. 130-139.

[111] Tester, et al. (1995). Effects of elevated growth temperature and carbon dioxide levels on some physicochemical properties of wheat starch. Journal of Cereal Science, 22, pp. 63-71. 
[112] Debon, et al. (1998). Effect of temperature on the synthesis, composition and physical properties of potato microtuber starch. Journal of the Science of Food and Agriculture, 76, pp. 599-607.

[113] Noda, et al. (2001). Effect of soil temperature on starch properties of sweet potatoes. Carbohydrate Polymers, 44, pp. $239-246$.

[114] Thomas, et al. (2003). Elevated temperature and carbon dioxide effects on soybean seed composition and transcript abundance. Crop Science, 43, p. 1548.

[115] Izquierdo, et al. (2002). Night temperature affects fatty acid composition in sunflower oil depending on the hybrid and the phenological stage. Field Crops Research, 77, pp. 115-126.

[116] Williams, et al. (1995). The effects of elevated temperature and atmospheric carbon dioxide concentration on the quality of grain lipids in wheat (Triticum aestivum L.) grown at two levels of nitrogen application. Plant, Cell and Environment, 18, pp. 999-1009.

[117] Morison, J. I. L. \& Lawlor, D. W. (1999). Interactions between increasing $\mathrm{CO}_{2}$ concentration and temperature on plant growth. Plant, Cell and Environment, 22, pp. 659-682.

[118] Flagella, et al. (2002). Changes in seed yield and oil fatty acid composition of high oleic sunflower (Helianthus annuus L.) hybrids in relation to the sowing date and the water regime. European Journal of Agronomy, 17, pp. 221-230.

[119] Di Caterina, et al. (2007). Influence of salt stress on seed yield and oil quality of two sunflower hybrids. Annual Applied Biology, 151, pp. 145-154.

[120] Dornbos, D. L. \& Mullen, R. E. (1992). Soybean seed protein and oil contents and fatty acid composition adjustments by drought and temperature. Journal of the American Oil Chemists' Society, 69, pp. 228-231.

[121] Taarit, et al. (2010). Changes in fatty acid and essential oil composition of sage (Salvia officinalis L.) leaves under NaCl stress. Food Chemistry, 119, pp. 951-956.

[122] Rakszegi, et al. (2014). Effect of heat and drought stress on the structure and composition of arabinoxylan and beta-glucan in wheat grain. Carbohydrate Polymer, 102, pp. 557-565.

[123] Oktem, A. (2008). Effect of water shortage on yield, and protein and mineral compositions of drip-irrigated sweet corn in sustainable agricultural systems. Agricultural Water Management, 95, pp. 1003-1010.

[124] Ti, et al. (2010). Differential responses of yield and selected nutritional compositions to drought stress in summer maize grains. Journal of Plant Nutrition, 33, pp. 1811-1818. 